\title{
A Cloud based Mobile Healthcare System
}

\author{
Mangesh Manake \\ Savitribai Phule Pune University, \\ D. Y. Patil Institute of Engg \& Tech., \\ Pune, India- 410507
}

\begin{abstract}
The Healthcare system is the mobile application that stores the large amount of private data of a patient's or users. Since the collected Patient Health Information (PHI) is private information of patients and plays a critical role in medical diagnosis and treatment. It is essential to strictly limit the access of these data to authorized users only in order to ensure the security of these data and preserve the patients' privacy. However, the security and privacy protection of the stored data is a major unsolved issue. So, the proposed system provides the security for that users data. The mobile healthcare applications provide easy access to medical care information anytime and anywhere. Recently health is important issue in our daily life. We must have to take care of our health. But this is not possible every time, sometimes because of busy schedule we can't take care of our health. So, I proposed to build an application of mobile healthcare System using cloud. The system provides a disease oriented information. Main features of this health care system is to provide medical camp with their location, disease oriented information, primary solution to particular disease and hospital locations. The system also provides privacy. This system or application is most useful in emergency cases. With the help of this system patients can check specialization of doctor and according to he/she can take the appointment with that particular doctor. Patients or user can also check for medical camps and then he/she can also register to that camp and take the appointment.
\end{abstract}

Keywords: Access control, Cloud computing, Mobile Health, Privacy

\section{INTRODUCTION}

Recently health is important issue in our daily life. A large amount of personal data for medical purpose is involved in PHI and people start to realize that they would completely lose control over their personal information. According to the government website, around millions of patients' health information was leaked in the past few years. There is need for keeping medical data private and limiting the access. The proposed healthcare system is inspired by the power, flexibility, cost efficiency, and convenience of the cloudbased data. Cloud is a large server in which large number of data is stored and cloud computing is computing in which large group of remote server are networked to allow centralized data storage and online access to computer services or resources. Cloud computing is computing based on the internet. We use the cloud which can be considered as a service offered to mobile users (SaaS-Software as a Service). User will transfer the data to the service provider via the internet and access their stored data using software provided by storage provider. Now a day's all are busy in their work. Because of lack of time they can neglect their health problems and because of busy schedule they can't meet to the doctor. So, there is need to everyone of taking care of their health. Because of changing atmosphere different diseases may occur. Sometimes this disease will be very dangerous, person can die. So, to solve this all problems of peoples I propose to build an application in which disease oriented all information will be stored using cloud. People can access this information easily and take care of their health. We also provide the privacy with the help of private cloud. There is large amount of personal health data involved in Personal Health Information. There might be no assurance of security or privacy of these personal health records. Cloud is a service which is offered to mobile user. Main features of proposed system is to maintain information of medical camps, online doctor's, nearby hospitals etc. In our system, we provide a list of doctor's with their name, specialization, address. We also provide the list of hospitals and find the nearby hospitals through Google map. It also provide different medical camp list and their current location and how much distance user will long from particular medical camp. It also provides each medical camp's details. It also shows the shortest path using Google Map for medical camp where you will be standing. If patient want to register in particular medical camp they can also register through our system. Same way, patient can also online register to take doctor's appointment.

\section{RELATED WORK}

The system of Ming Li, Shucheng Yu, and Yao Zheng is based on multi-authority attribute based encryption to achieve fine-grained and scalable data access control for personal health record. They leverage attribute based encryption technique to encrypt each patient's PHI file. This paper is for find grain access control by the use of emergency attributes the system allows break- glass access [1]. The system of LinkeGuo, , Chi Zhang, Jinyuan Sun, and Yuguang Fang propose a decentralized system that leverages users' verifiable attributes to authenticate each other while preserving attribute and identity privacy. They design authentication strategies with progressive privacy requirements in different interactions among participating entities [2].

The system of Ganesan, Harish, provides authentication based upon the types of users who is authorized to use the application. Security is provided through the process of Encryption and data are retrieved through decryption. This system will provide security in delivering the EMR of patients [8]. The system of Wan-Ting Liu , Wei-Shan Chen monitors the patient's where about and then sends the patient's physiological signals to the hospital. They implement healthcare box that collects ECG, video and location of the patient[9]. In this paper, the system is a Radiology Information System (RIS), a component of e-Healthcare Information System (HIS) .The RIS system will be hosted on a hybrid cloud where the private cloud is used to store the sensitive data of the patients and the public cloud is used to store the public data [10].

The Yan Tang, Zhenyu Chen, Yiqiang Chen paper presents a mobile phone based personal and pervasive health care system for the elderly to monitor their daily life and physiological indexes [7].The system of S. Yu, C. Wang, K. Ren, and W. Lou allow the data owner to delegate most of the computation tasks involved in fine-grained data access control 
to untrusted cloud servers without disclosing the underlying data contents. They achieve this goal by exploiting and uniquely combining techniques of attribute-based encryption (ABE).The system of L. Guo, C. Zhang, J. Sun, and Y. Fang provide authentication strategies with progressive privacy requirements among patients or between patients and physicians [5].

\section{LITERATURE REVIEW}

Table 1: Literature Review

\begin{tabular}{|c|c|c|c|}
\hline $\begin{array}{l}\mathrm{S} \\
\mathrm{r} .\end{array}$ & Paper Name & $\begin{array}{c}\text { Conference } \\
\text { Name, } \\
\text { Authors/year }\end{array}$ & Approach \\
\hline 1 & $\begin{array}{l}\text { Scalable and } \\
\text { secure } \\
\text { sharingof } \\
\text { personal health } \\
\text { records in } \\
\text { cloud } \\
\text { computing } \\
\text { using attribute- } \\
\text { based } \\
\text { encryption. }\end{array}$ & $\begin{array}{l}\text { IEEE Trans. } \\
\text { Parallel Distrib. } \\
\text { Syst., vol. 24, no. } \\
\text { 1, pp. 131-143. } \\
\text { M. Li, S. Yu, Y. } \\
\text { Zheng, K. Ren, } \\
\text { andW. Lou, } \\
\text { Jan. 2013. }\end{array}$ & $\begin{array}{l}\text { This system } \\
\text { utilizes the } \\
\text { multi-authority } \\
\text { attribute based } \\
\text { encryption. }\end{array}$ \\
\hline 2. & $\begin{array}{l}\text { A Privacy } \\
\text { Preserving } \\
\text { Attribute- } \\
\text { Based } \\
\text { Authentication } \\
\text { System for } \\
\text { Mobile } \\
\text { Health } \\
\text { Networks }\end{array}$ & $\begin{array}{l}\text { IEEE } \\
\text { Transactions on } \\
\text { mobile } \\
\text { computing, vol. } \\
\text { 13, no. 9. } \\
\text { LinkeGuo, } \\
\text { Student Member, } \\
\text { Chi Zhang, } \\
\text { Jinyuan Sun, } \\
\text { andYuguang } \\
\text { Fang, Sep } 2014\end{array}$ & $\begin{array}{l}\text { The system } \\
\text { design } \\
\text { authentication } \\
\text { strategies with } \\
\text { progressive } \\
\text { privacy } \\
\text { requirements in } \\
\text { different } \\
\text { interactions } \\
\text { among } \\
\text { Participating } \\
\text { entities. }\end{array}$ \\
\hline 3. & $\begin{array}{l}\text { PPCare:A } \\
\text { personal and } \\
\text { pervasive } \\
\text { health care } \\
\text { system for the } \\
\text { elderly }\end{array}$ & 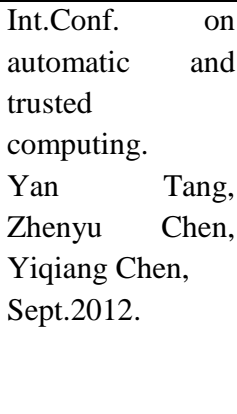 & $\begin{array}{l}\text { The system } \\
\text { present a } \\
\text { mobile phone } \\
\text { based personal } \\
\text { and pervasive } \\
\text { healthcare } \\
\text { system to } \\
\text { monitor } \\
\text { physiological } \\
\text { indexes. }\end{array}$ \\
\hline 4. & $\begin{array}{l}\text { Design and } \\
\text { development of } \\
\text { secured m- } \\
\text { healthcare } \\
\text { system }\end{array}$ & $\begin{array}{l}\text { Science and } \\
\text { management } \\
\text { (ICAESM),2012I } \\
\text { nt.conf. } \\
\text { Ganesan,Harish. } \\
\text { March 2012 }\end{array}$ & $\begin{array}{l}\text { This system is } \\
\text { provide the } \\
\text { security in } \\
\text { delivering EMR } \\
\text { of patients. }\end{array}$ \\
\hline
\end{tabular}

\section{ARCHITECTURE}

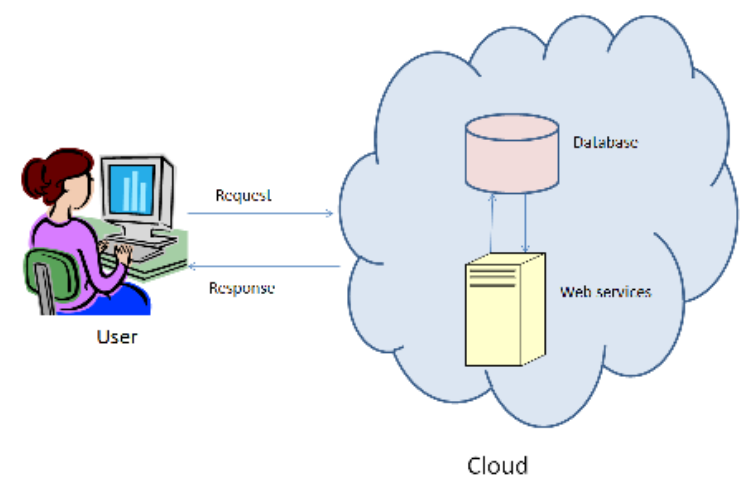

Figure. 1 Cloud assisted mobile health network

The Healthcare system is the mobile application that stores the large amount of private data of a patient's or users. This application provides large amount of disease oriented information. This application also provides different medical camps information with their location. We use the cloud infrastructure to store all disease oriented information and users private data. Only authenticated user can use this application. In this application there are two sections private and public. In private section users private data will be stored and in public section all public data will be stored. Public data such as all disease oriented information, solutions to each disease, medical camps information. When user wants to search any information, first user must have to be selecting the private or public section. If user wants to search in public section, then user will send the request to the browser. Then this request will be passing to the server by the browser and it will fetch the data from the server related to request and give response back to browser and then browser will display this response to user. If user wants to store the personal health data then it will use private section. We provide the privacy to the private data of user using secret key. We keep the entire user's private data in encrypted form. So, unauthorized person cannot access the user's private data. When user will search his private data then automatic secret key will be generated and this key will be passed to user's mail id. When user wants to fetch the data then it will get the data in encrypted form. So user must have to decrypt the data. When user click on decrypt it will ask for secret key which is user's email id. Using this secret key user can decrypt the data. 


\section{FUTURE WORK}

As a future work, I plan to device mechanism through which user can communicate with doctors or we can say that face to face communication of users and doctors. I also plan to devise mechanisms that can detect whether users' health data have been illegally distributed, and identify possible source(s) of leakage. In future Mobile health apps exist in a gray zone between medical devices, which are highly regulated, and computer applications, which aren't regulated much at all. Whenever an app is used to facilitate communication between a medical device, such as a blood pressure monitor and a mobile phone that transmits data to a physician's office.

\section{CONCLUSION}

In this paper, I proposed to build an application of mobile healthcare System using cloud. In previous papers, they provide privacy for health data using the private cloud and public cloud used to store the public data. As they use both private and public cloud they require more storage space than our system. Silent features of health care system is to provide medical camp with their location, provide disease oriented information, provide primary solution to particular disease, and provide hospital locations. This system provides a disease oriented information. This application provides easy access to medical care information anytime and anywhere. We also provide privacy. This system or application is most useful in emergency cases. These systems provide the different medical camps with their name and purpose. This system also provides the nearest hospital location.

\section{ACKNOWLEDGMENTS}

The author would like to thanks to the publishers, researchers for making their resources available. We also thank to the college authority for supporting me and providing required information. We would also like to thank our friends and family members.

\section{REFERENCES}

[1] M. Li, S. Yu, Y. Zheng, K. Ren, and W. Lou, "Scalable and secure sharingof personal health records in cloud computing using attribute-based encryption,'IEEE Trans. Parallel Distrib. Syst., vol. 24, no. 1, pp. 131-143, Jan. 2013.

[2] LinkeGuo, Student Member, Chi Zhang, Jinyuan Sun, andYuguang Fang, "A Privacy-Preserving Attribute-Based
Authentication System for Mobile Health Networks," IEEE Transactions on mobile computing, vol. 13, no. 9, September 2014.

[3] J. Sun, X. Zhu, and Y. Fang, "Privacy and emergency response in ehealthcareleveraging wireless body sensor networks," IEEE WirelessCommun., vol. 17, no. 1, pp. 66-73, Feb. 2010.

[4] S. Yu, C. Wang, K. Ren, and W. Lou, “Achieving secure, scalable, and fine-grained data access control in cloud computing," presented at the IEEE Conf. Comput. Commun., San Diego, CA, USA, Mar. 2010.

[5] L. Guo, C. Zhang, J. Sun, and Y. Fang, "PAAS: Privacypreserving attribute-based authentication system for eHealth networks," in Proc.IEEE Intl. Conf. Distrib. Comput. Syst., Jun. 2012, pp. 224-233.

[6] J. Sun, X. Zhu, C. Zhang, and Y. Fang, "Security and Privacy for Mobile Healthcare (m-Health) Systems", in Handbook on Securing Cyber-Physical Infrastructure, S. Das, K. Kant, and N. Zhang, Eds. Amsterdam, TheNetherlands: Elsevier, 2011.

[7] Yan Tang, Zhenyu Chen, Yiqiang Chen.” PPCare:A personal and pervasive health care system for the elderly",Int.Conf. on automatic and trusted computing,Sept.2012.

[8] Ganesan, Harish," Design and development of secured mhealthcare system", Science and management (ICAESM),Int.conference, March 2012.

[9] Wan-Ting Liu,Wei-Shan Chen, Yung-wei Lu," Design and implementation of a healthcare system with fall detection", Bioelectronics and Bioinformatics (ISBB), Int. Symposium ,Nov.2011.

[10] Yu, W.D. Kollipara, M. Penmetsa, R.Elliadka, S.”A distributed storage solution for cloud based e-Healthcare Information System ",e-Health Networking, Applications \& Services (Healthcom), Int. Conference, Oct 2013 